\title{
Does anthropogenic phosphorus input reduce soil microbial resource allocation to acquire nitrogen relative to carbon?
}

\author{
Taiki Mori a,*, Ryota Aoyagi b \\ a Department of Forest Site Environment, Forestry and Forest Products Research Institute, Tsukuba, Ibaraki, Japan \\ b Smithsonian Tropical Research Institute, Panama City, Panama
}

\section{Article Info}

Received : 01.03.2018

Accepted : 10.12.2018

\begin{abstract}
We aimed to test if anthropogenic $\mathrm{P}$ input into ecosystems reduces microbial resource allocation to acquire $\mathrm{N}$ (and alleviate $\mathrm{N}$ shortage if any) because microbes no longer produce N-rich phosphatase for $\mathrm{P}$ acquisition. Literatures reporting the effect of $\mathrm{P}$ fertilization on C-acquiring ( $\beta$-1,4-glucosidase, $B G)$ and $\mathrm{N}$-acquiring ( $\beta-1,4-\mathrm{N}$ acetylglucosaminidase, NAG, which also acquires $C$ ) enzymes were collected and synthesized. We predicted that P addition elevates BG:NAG especially in P-poor ecosystems because $\mathrm{P}$ addition alleviates $\mathrm{N}$ shortage and reduces the microbial resource allocation to acquire $\mathrm{N}$ relative to $\mathrm{C}$. The synthesized data demonstrated that $\mathrm{P}$ fertilization occasionally reduced BG:NAG, which is inconsistent with the prediction. However, this might not mean that the initial hypothesis was rejected. Stimulated microbial activity and turnover by $P$ fertilization could have caused microbes depend the $C$ sources more on chitin (and peptidoglycan) compared with on cellulose because chitin (and peptidoglycan) is a main component of microbial body and re-provided through microbial turnover. The changes in $\mathrm{C}$ resources accompanied by the altered $\mathrm{P}$ availability may have largely influenced BG:NAG, masking the role of BG:NAG for indicating microbial resource allocation to $C$ and $N$ acquisitions.
\end{abstract}

Keywords: $\beta$-1,4-glucosidase (BG), $\beta$-1,4-N-acetylglucosaminidase (NAG), ecoenzymatic stoichiometry, phosphatase, phosphorus fertilization.

(c) 2019 Federation of Eurasian Soil Science Societies. All rights reserved

\section{Introduction}

Marklein and Houlton (2012) proposed in their meta-analysis that anthropogenic nitrogen (N) elevation can compensate phosphorus (P) shortage of biota through elevating phosphatase production, because $\mathrm{N}$-rich phosphatase (C:N ratio of protein is generally up to 4) synthesis requires a large amount of $\mathrm{N}$ (Olander and Vitousek; 2000; Treseder and Vitousek, 2001; Houlton et al., 2008). From their hypothesis, it can be indicated that $\mathrm{P}$ shortage elevates microbial $\mathrm{N}$ requirement in order to produce the $\mathrm{N}$-rich phosphatase and accelerates $\mathrm{N}$ shortage (if any). Accordingly, anthropogenic $\mathrm{P}$ inputs into ecosystems can reduce microbial resource allocation to acquire $\mathrm{N}$ (relative to $\mathrm{C}$ ) and alleviate $\mathrm{N}$ shortage because microbes reduce the production of the $\mathrm{N}$-rich phosphatase in P-rich conditions.

Many previous studies assumed that the resource allocation of microbes to acquire nutrients and energy could be expressed as ecoenzymatic stoichiometry, i.e., ratios of extracellular enzymes targeting $\mathrm{C}, \mathrm{N}$ and $\mathrm{P}$ (Sinsabaugh et al., 2008, 2009; Waring et al., 2014). Among a variety of extracellular enzymes targeting C, N, and $\mathrm{P}, \quad \beta-1,4$-glucosidase (BG, catalyzing the terminal reaction in cellulose degradation), $\beta-1,4-\mathrm{N}$ acetylglucosaminidase (NAG, catalyzing the terminal reaction in chitin degradation), and acid (or alkaline) phosphatase (AP, hydrolyzing organic phosphorus) has been measured most widely (Olander and Vitousek,

\footnotetext{
${ }^{*}$ Corresponding author.

Department of Forest Site Environment, Forestry and Forest Products Research Institute, Matsunosato 1, Tsukuba, Ibaraki 3058687, Japan

Tel.: +81757536080

E-mail address: taikimori7@gmail.com

e-ISSN: $2147-4249$ DOI: $10.18393 /$ ejss.498039
} 
2000; Allison and Vitousek, 2005; Sinsabaugh et al., 2009; Turner and Wright, 2014; Waring et al., 2014; Jian et al., 2016). Thus the ratio of BG and NAG (BG:NAG), and of BG and AP (BG:AP) are often used as indicators of microbial resource allocation to the acquisition of $\mathrm{N}$ and P relative to C, respectively (Sinsabaugh et al., 2008, 2009; Turner and Wright, 2014; Waring et al., 2014; Moorhead et al., 2016; Zhou et al., 2017; Rosinger et al., 2018; Tatariw et al., 2018), although few studies recently suggested that the BG:NAG may not always indicate the microbial resource allocation to the acquisition of $\mathrm{N}$ relative to $\mathrm{C}$ because NAG can be also produced for acquiring $\mathrm{C}$ as well as $\mathrm{N}$ (Mori et al., 2018a, b; Wang et al., 2018).

Based on the above hypothesis and assumption, it is predicted that $\mathrm{P}$ addition would elevate BG:NAG because $\mathrm{P}$ addition reduces the microbial resource allocation to acquire $\mathrm{N}$ relative to $\mathrm{C}$ through reducing the $\mathrm{N}$ requirement to synthesize phosphatase (note that $\mathrm{P}$ addition does not necessarily reduce the absolute resource investment on $\mathrm{N}$ acquisition). The response ratio of $\mathrm{BG}$ :NAG to $\mathrm{P}$ addition would be larger in $\mathrm{P}$-poor ecosystems where BG:AP is smaller (Figure 1). We also need to consider P-poor but N-rich conditions (such as areas with extremely high $\mathrm{N}$ deposition or fertilized with $\mathrm{N}$ ), where the reduced requirement of $\mathrm{N}$ in relation to $P$ addition would not affect BG:NAG because NAG is probably produced targeting $C$ acquisition rather than $\mathrm{N}$ (Mori et al. 2018a,b; Wang et al. 2018) (note that chitin contains both $\mathrm{N}$ and C) (Figure 2). In such conditions, $\mathrm{P}$ addition would not elevate BG:NAG (Figure 1). Overall, the relationship between BG:AP and the response ratio of $\mathrm{BG}: \mathrm{NAG}$ to $\mathrm{P}$ addition is predicted as follows: (i) the response ratio of $\mathrm{BG}$ :NAG to $\mathrm{P}$ fertilization would be higher than 1 and become larger as BG:AP decreases; or (ii) BG:NAG does not change in response to $\mathrm{P}$ addition if the soil is rich in $\mathrm{N}$ (response ratio is around 1) (Figure 1).

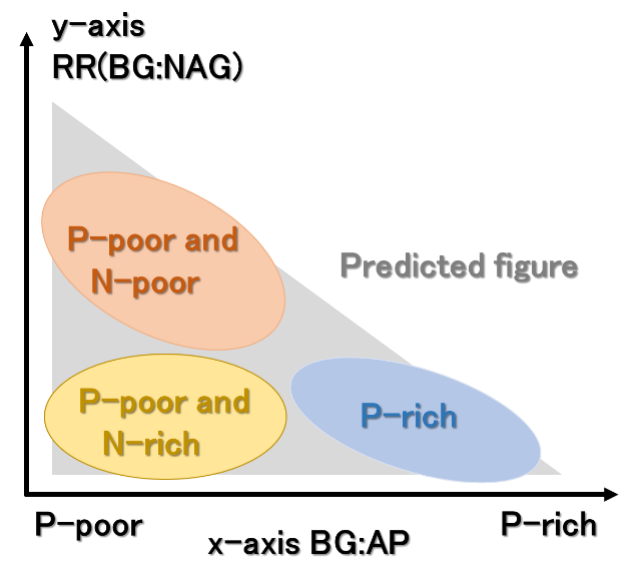

Figure 1. The predicted relationship between BG:AP and the response ratio of BG:NAG to P addition. RR(BG:NAG) represents the response ratio of $\mathrm{BG}: \mathrm{NAG}$ to $\mathrm{P}$ addition.

\section{RR(BG:NAG ratio) to decrease in N requirement}

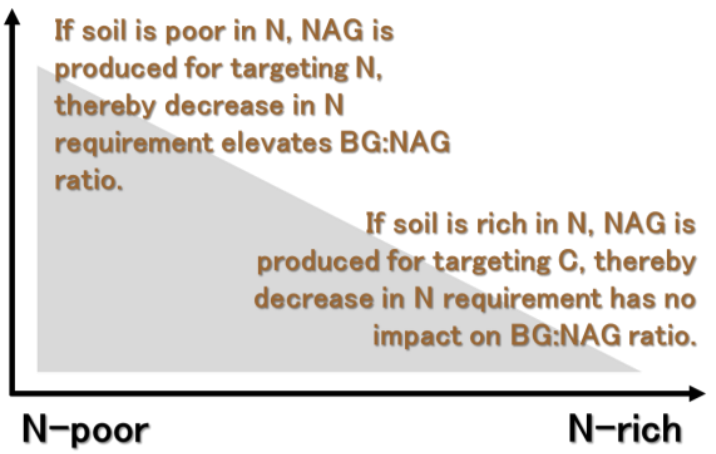

Figure 2. Predicted response of BG:NAG to a decrease in N requirement. RR(BG:NAG) represents the response ratio of BG:NAG to a decrease in N requirement. If soil is poor in N, NAG is produced for targeting organic N. In such a case, a decrease in $\mathrm{N}$ requirement reduces microbial allocation on $\mathrm{N}$-acquiring enzyme (NAG) and as a result BG:NAG will be elevated. Meanwhile, if soil is rich in N, NAG is produced for targeting $\mathrm{C}$, thereby a decrease in $\mathrm{N}$ requirement has no impact on BG:NAG.

In this study, we aimed to test if anthropogenic $\mathrm{P}$ input into ecosystems reduces microbial resource allocation to acquire $\mathrm{N}$ (and alleviate $\mathrm{N}$ shortage if any) by collecting the literatures reporting the effect of $\mathrm{P}$ fertilization on the activities of extracellular enzymes including BG, NAG, and AP. 


\section{Material and Methods}

We collected the literatures reporting the effects of P addition on the activities of NAG and BG. We used the search engine Web of Science to collect published literatures with the following combinations of key words for searching; ("phosph* add*" OR "P add*" OR "phosph* elevat*" OR "P elevat*" OR "phosph* fertiliz*" OR "P fertiliz*" OR "phosph* appl*" OR "P appl*"OR "phosph* enrich*" OR "P enrich*") AND (glucosidase OR $\beta$ glucosidase OR " $\beta$ glucosidase" OR BG OR $\beta$ G) AND (NAG OR chitinase OR $\beta$-1,4-N-acetyl- $\beta$-glucosaminidase OR "N-acetyl $\beta$-glucosaminidase" OR glucosaminidase). All papers collected in the above procedure reported AP activity as well as BG and NAG activities, which enabled us to evaluate the relationship between BG:AP and the response ratio of BG:NAG to $\mathrm{P}$ addition. We compensated the literature list by using other search engines, Google and Google Scholar, because several papers were not collected by the procedure. Since only a few number of papers were available for our research purpose, the data taken in the same site but with different types of nutrient addition (e.g., comparison between data in N-added and NP-added site) or different soil layer were counted as different data points (Table 1).

\section{Results and Discussion}

We found 29 data points from 9 literatures (Table 1). At the first glance, the relationship between BG:AP and the response ratio of BG:NAG to $\mathrm{P}$ fertilization (Figure 3) seems consistent with the predicted pattern (Figure 1): As BG:AP increased up to 0.5, the response ratio of BG:NAG to P fertilization declined (Figure 3). However, there were critical differences between the result and the prediction. We observed that response ratios of BG:NAG to $P$ addition were lower than 1 in several cases (i.e., $P$ addition reduced BG:NAG). Originally, we assumed that (i) the response ratio of BG:NAG to $P$ fertilization should be higher than 1 if $P$ fertilization reduces microbial $\mathrm{N}$ requirement, or (ii) BG:NAG does not change in response to $\mathrm{P}$ addition if the soil is rich in $\mathrm{N}$ (response ratio is around 1). The lower response ratio than 1 may indicate that the $\mathrm{P}$ addition increased $\mathrm{N}$ requirement relative to $\mathrm{C}$ requirement by biota. Although we cannot completely deny the possibility, it is less likely because $\mathrm{P}$ fertilization reduces $\mathrm{N}$-rich phosphatase production (Marklein and Houlton, 2012). Thus the present analysis failed to testify the hypothesis: anthropogenic P input into ecosystems reduces microbial resource allocation to acquire $\mathrm{N}$.

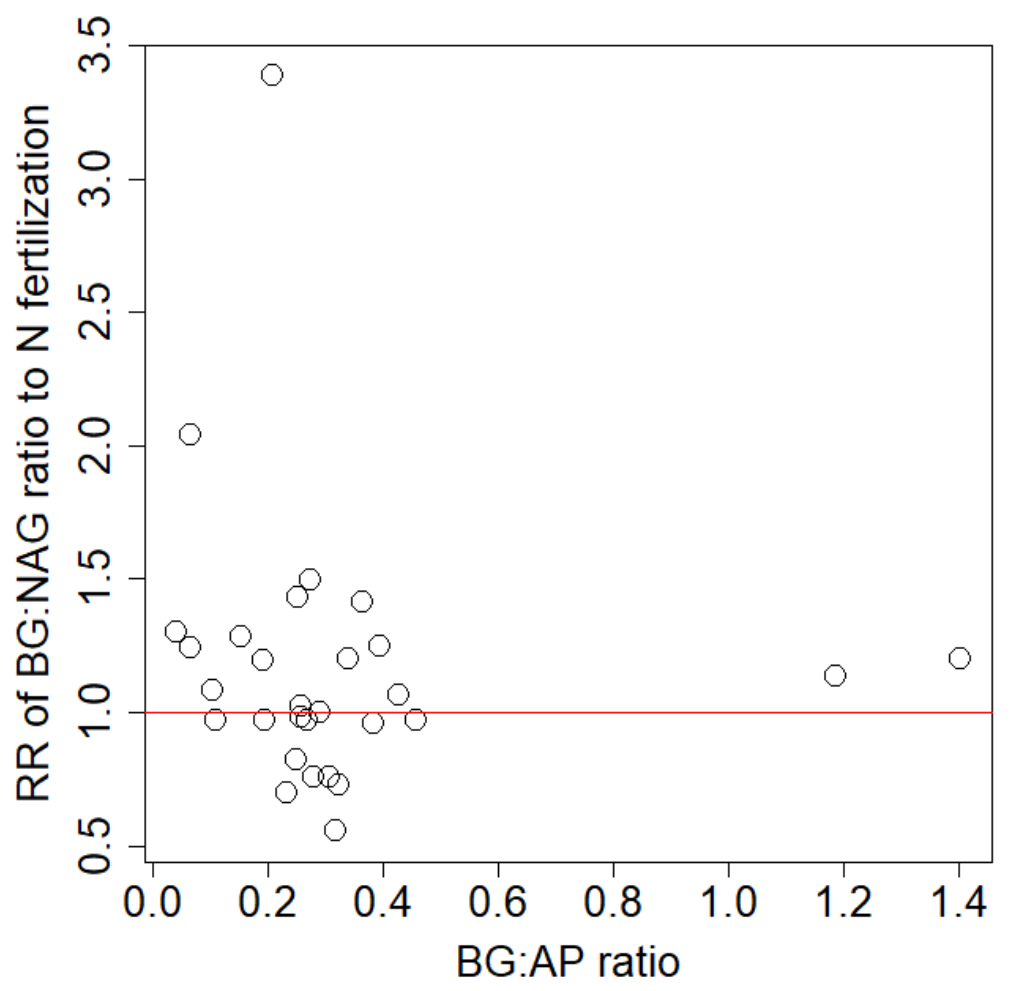

Figure 3. The relationship between BG:AP and the response ratio of BG:NAG to $\mathrm{P}$ addition in no $\mathrm{P}$ controls. This figure was drawn using data taken from literatures. RR(BG:NAG) represents the response ratio of BG:NAG to P addition. 1:1 line was drawn in the figure. 


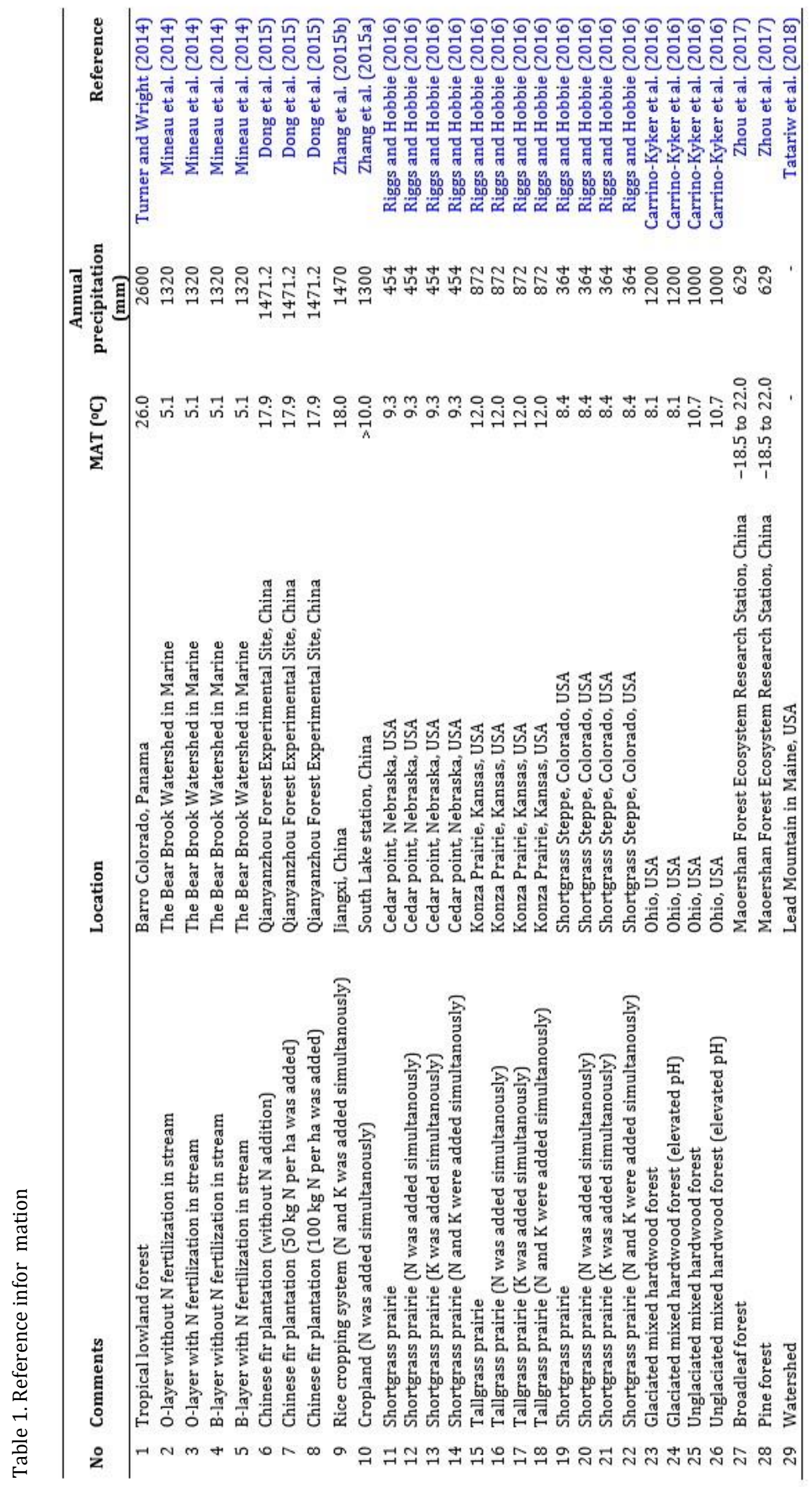


The discrepancy between our predictions and the result could be explained by an altered $\mathrm{C}$ resource composition. It was reported that cellulose decomposition was stimulated by P fertilization (Kaspari et al., 2008; Fanin et al., 2015), which leads a decrease in BG-targeting C in soils (i.e., cellulose). Although the stimulated cellulose decomposition is associated with elevated BG activity, the BG:NAG ratio could not be altered if decomposition of chitin and peptidoglycan (NAG is involved in the degradation of peptidoglycan, as well as chitin) is equally stimulated by P fertilization (which needs to be tested). Instead, the cellulose:chitin (and peptidoglycan) ratio could be lowered because chitin and peptidoglycan is re-provided in soils through microbial turnover as as chitin and peptidoglycan are main components of microbial body. By contrast, cellulose is basically not provided from the microbial body. Accordingly, microbial activity could be more chitin (and peptidoglycan)-dependent under P-added conditions, leading to a larger NAG activity relative to BG (lower BG:NAG) because microbes shift enzyme activity for targeting more-abundant substrates. If this is true, at least in some cases, changes in BG:NAG represent the progress of decomposition stage or the strength of microbial activity rather than a microbial allocation on $\mathrm{C}$ and $\mathrm{N}$ acquisition, which challenges the idea suggested in previous studies (e.g., Waring et al., 2014). Although this new hypothesis still lacks definitive evidences, it potentially explains the synthesized pattern. Monitoring the BG:NAG ratios as well as decomposition ratios of cellulose and chitin both in manipulated $\mathrm{N}$-shortage and $\mathrm{N}$-rich conditions in a laboratory experiment may provide a chance to examine what actually controls the pattern of BG:NAG.

The present analysis failed to demonstrate the reduced $\mathrm{N}$ requirement by $\mathrm{P}$ fertilization, but this might not mean that the initial hypothesis was rejected. As discussed above, changes in $\mathrm{C}$ resources accompanied by the altered $P$ availability may have largely influenced BG:NAG, masking the role of BG:NAG for indicating microbial resource allocation to $\mathrm{C}$ and $\mathrm{N}$ acquisitions. Another indicator to access microbial $\mathrm{N}$ acquisition, which is not affected by the changes in $\mathrm{C}$ resources, is necessary for testing if $\mathrm{P}$ input into ecosystems reduces microbial resource allocation to acquire $\mathrm{N}$ and alleviate $\mathrm{N}$ shortage.

\section{Acknowledgement}

This study was financially supported by a grant from environmental research aid, The Sumitomo Foundation 153082 and Grant-in-Aid for JSPS Postdoctoral Fellowships for Research Abroad (28.601) to T Mori.

\section{References}

Allison, S.D., Vitousek, P.M., 2005. Responses of extracellular enzymes to simple and complex nutrient inputs. Soil Biology and Biochemistry 37(5): 937-944.

Carrino-Kyker, S.R., Kluber, L.A., Petersen, S.M., Coyle, K.P., Hewins, C.R., DeForest, J.L., Smemo, K.A., Burke, D.J., 2016. Mycorrhizal fungal communities respond to experimental elevation of soil $\mathrm{pH}$ and $\mathrm{P}$ availability in temperate hardwood forests. FEMS Microbiology Ecology 92(3):1-19.

Dong, W.Y., Zhang, X.Y., Liu, X.Y., Fu, X.L., Chen, F.S., Wang, H.M., Sun, X.M., Wen, X.F., 2015. Responses of soil microbial communities and enzyme activities to nitrogen and phosphorus additions in Chinese fir plantations of subtropical China. Biogeosciences 12(18): 5537-5546.

Fanin, N., Hättenschwiler, S., Schimann, H., Fromin, N., 2015. Interactive effects of C, N and P fertilization on soil microbial community structure and function in an Amazonian rain forest. Functional Ecology 29(1):140-150.

Houlton, B.Z., Wang, Y.P., Vitousek, P.M., Field, C.B., 2008, A unifying framework for dinitrogen fixation in the terrestrial biosphere. Nature 454:327-330.

Jian, S., Li, J., Chen, J., Wang, G., Mayes, M.A., Dzantor, K.E., Hui, D., Luo, Y., 2016. Soil extracellular enzyme activities, soil carbon and nitrogen storage under nitrogen fertilization: A meta-analysis. Soil Biology and Biochemistry 101:3243.

Kaspari, M., Garcia, M., Harms, K.E., Santana, M., Wright S.J., Yavitt, J.B., 2008. Multiple nutrients limit litterfall and decomposition in a tropical forest. Ecology Letters 11(1): 35-43.

Marklein, A.R., Houlton, B.Z., 2012. Nitrogen inputs accelerate phosphorus cycling rates across a wide variety of terrestrial ecosystems. The New Phytologist 193(3): 696-704.

Mineau, M.M., Fatemi, F.R., Fernandez, I.J., Simon, K.S., 2014. Microbial enzyme activity at the watershed scale: Response to chronic nitrogen deposition and acute phosphorus enrichment. Biogeochemistry 117(1): 131-142.

Moorhead, D.L., Sinsabaugh, R.L., Hill, B.H., Weintraub, M.N., 2016. Vector analysis of ecoenzyme activities reveal constraints on coupled C, N and P dynamics. Soil Biology and Biochemistry 93:1-7.

Mori, T., Imai, N., Yokoyama, D., Kitayama, K., 2018a. Effects of nitrogen and phosphorus fertilization on the ratio of activities of carbon-acquiring to nitrogen-acquiring enzymes in a primary lowland tropical rainforest in Borneo, Malaysia. Soil Science and Plant Nutrition 64(5): 554-557.

Mori, T., Lu, X., Aoyagi, R., Mo, J., 2018b. Reconsidering the phosphorus limitation of soil microbial activity in tropical forests. Functional Ecology 32:1145-1154. 
Olander, L.P., Vitousek, P.M., 2000 Regulation of soil phosphatase and chitinase activity by N and P availability. Biogeochemistry 49(2): 175-190.

Riggs, C.E., Hobbie, S.E., 2016. Mechanisms driving the soil organic matter decomposition response to nitrogen enrichment in grassland soils. Soil Biology and Biochemistry 99: 54-65.

Rosinger, C., Rousk, J., Sandén, H., 2018, Can enzymatic stoichiometry be used to determine growth-limiting nutrients for microorganisms? - A critical assessment in two subtropical soils. Soil Biology and Biochemistry 128: 115-126.

Sinsabaugh, R.L., Hill, B.H., Follstad Shah, J.J., 2009. Ecoenzymatic stoichiometry of microbial organic nutrient acquisition in soil and sediment. Nature 462:795-798.

Sinsabaugh, R.L., Lauber, C.L., Weintraub, M.N., Ahmed, B., Allison, S.D., Crenshaw, C., Contosta, A.R., Cusack, D., Frey, S., Gallo, M.E., Gartner, T.B., Hobbie, S.E., Holland, K., Keeler, B.L., Powers, J.S., Stursova, M., Takacs-Vesbach, C., Waldrop, M.P., Wallenstein, M.D., Zak, D.R., Zeglin, L.H., 2008. Stoichiometry of soil enzyme activity at global scale. Ecology Letters 11(11): 1252-1264.

Tatariw, C., MacRae, J.D., Fernandez, I.J., Gruselle' M.C., Salvino, C.J., Simon, K.S., 2018. Chronic nitrogen enrichment at the watershed scale does not enhance microbial phosphorus limitation. Ecosystems 21(1): 178-189.

Treseder, K.K., Vitousek, P.M., 2001. Effects of soil nutrient availability on investment in acquisition of $\mathrm{N}$ and $\mathrm{P}$ in Hawaiian rainforests. Ecology 82: 946-954.

Turner, B.L., Wright, S.J., 2014. The response of microbial biomass and hydrolytic enzymes to a decade of nitrogen, phosphorus, and potassium addition in a lowland tropical rain forest. Biogeochemistry 117(1): 115-130.

Wang, C., Lu, X., Mori, T., Mao, Q., Zhou, K., Zhou, G., Nie, Y., Mo, J., 2018. Responses of soil microbial community to continuous experimental nitrogen additions for 13 years in a nitrogen-rich tropical forest. Soil Biology and Biochemistry 121: 103- 112.

Waring, B.G., Weintraub, S.R., Sinsabaugh, R.L., 2014. Ecoenzymatic stoichiometry of microbial nutrient acquisition in tropical soils. Biogeochemistry 117(1): 101-113.

Zhang, Q., Zhou, W., Liang, G., Sun, J., Wang, X., He, P., 2015a. Distribution of soil nutrients, extracellular enzyme activities and microbial communities across particle-size fractions in a long-term fertilizer experiment. Applied Soil Ecology 94: 59-71.

Zhang, X., Dong, W., Dai, X., Schaeffer, S., Yang, F., Radosevich, M., Xu, L., Liu, X., Sun, X., 2015b. Responses of absolute and specific soil enzyme activities to long term additions of organic and mineral fertilizer. Science of The Total Environment 536:59-67.

Zhou, Z., Wang, C., Jin, Y., 2017. Stoichiometric responses of soil microflora to nutrient additions for two temperate forest soils. Biology and Fertility of Soils 53(4): 397-406. 